\title{
Response of the left ventricle to nitroglycerin in patients with and without mitral regurgitation ${ }^{1}$
}

\author{
Allan D. Sniderman, ${ }^{2}$ Derek G. F. Marpole, ${ }^{2}$ Wilfred H. Palmer, and Ernest L. Fallen \\ From the Cardiology Division, McGill University Clinic, Royal Victoria Hospital, Montreal, P.Q., Canada
}

Left ventricular cineangiographic volumes and haemodynamics were measured before and after nitroglycerin in 17 patients. The average end-diastolic volume was reduced by nitroglycerin from 82 to $69 \mathrm{ml} / \mathrm{m}^{2}(P<0 \cdot 001)$ in 8 patients without mitral regurgitation and from 159 to II6 ml/ $\mathrm{m}^{2}(P<0.005)$ in 9 patients with mitral regurgitation. The haemodynamic response, however, differed in the two circumstances. Whereas nitroglycerin increased the average ejection fraction from 0.53 to $0.64(P<0.01)$ in the patients without mitral regurgitation, the ejection fraction was decreased by the drug from 0.65 to $0.52(P<0.005)$ in the mitral regurgitation patients. However, the forward cardiac output was not changed by nitroglycerin; the reduction in ejection fraction in the patients with mitral regurgitation must therefore have been due to a reduction in backflow into the left atrium. This indicates that nitroglycerin reduced the severity of mitral regurgitation in association with (and probably as a result of) a reduction in heart size.

Mean circumferential fibre shortening rate was reduced $(P<0.05)$ by nitroglycerin in 5 of the patients with mitral regurgitation who also had coronary artery disease but not for this group of patients as a whole, nor for the group without mitral regurgitation (all with coronary artery disease). Average left ventricular enddiastolic pressure was reduced by nitroglycerin in the patients without mitral regurgitation $(P<0 \cdot 0 I)$ but not in the patients with mitral regurgitation.

Although nitroglycerin has been used clinically since 1879 , its haemodynamic consequences remain incompletely defined. The beneficial effect of nitroglycerin in angina has been ascribed to mechanisms which either reduce myocardial oxygen consumption by decreasing preload or afterload (Gorlin et al., 1959; Marchetti, Merlo, and Antognetti, 1964; Perloff, Ronan, and de Leon, I965) or improve the manner in which oxygen supply reaches the myocardium (Fam and McGregor, 1964).

Energy requirements in the intact heart are determined to a significant degree by ventricular size (Braunwald, 1969). Although two studies have shown a reduction in ventricular dimensions with nitrates (Lee, Sung, and Zaragoza, 1970; Williams, Glick, and Braunwald, 1965), no angiographic estimation of left ventricular volumes has been performed in the presence of nitroglycerin. In addition, since many patients taking nitroglycerin may have papillary muscle dysfunction or mitral regurgitation from other causes, it seemed pertinent to inquire

Received 22 October 1973.

1 Supported in part by a grant from the Medical Research Council of Canada.

${ }^{2}$ Recipients of Canadian Heart Foundation Fellowships. whether the effect of the nitrate on ventricular performance could be influenced by such preloaded states.

The present study was designed therefore to determine: (a) the effect of nitroglycerin on left ventricular volumes obtained by cineangiography and (b) the influence nitroglycerin may have on ventricular dimensions and haemodynamics in patients with and without mitral regurgitation.

\section{Subjects and methods}

Seventeen patients studied at the time of diagnostic cardiac catheterization were divided into two groups. Group I consisted of 8 patients without demonstrable mitral regurgitation, all of whom were suffering from angina and displayed angiographic evidence of coronary artery disease. Group 2 consisted of 9 patients with clinically and angiographically documented mitral regurgitation: 4 of these patients had coronary artery disease with papillary muscle dysfunction and 4 had isolated mitral regurgitation secondary to rheumatic heart disease; the remaining patient in this group (Case 13, Table) had both rheumatic mitral regurgitation and severe stenosis of the left anterior descending coronary artery.

All patients were studied in the resting post-absorptive 
state after premedication with intramuscular pethidine, $50 \mathrm{mg}$, and oral diazepam, 10 $\mathrm{mg}$. Catheterization of the left heart was performed via the transfemoral approach using a $100 \mathrm{~cm}$ multiple hole catheter. Left ventricular pressures were obtained with a Statham $\mathrm{P}_{23} \mathrm{Db}$ strain gauge transducer and recorded on a DR-8 Electronics for Medicine photographic recorder. Cine ventriculography was performed in the $30^{\circ}$ right anterior oblique position. Each powered injection of contrast material consisted of 50-60 ml meglumine diatrizoate delivered over 4 seconds directly into the left ventricular cavity. After a recovery period of 15 minutes, $0.6 \mathrm{mg}$ nitroglycerin was administered sublingually. Five minutes after complete absorption of the pill, the left ventricular cineangiogram was repeated in the same obliquity and with an identical amount of contrast material. Left ventricular systolic and end-diastolic pressures and heart rates were recorded immediately before each injection. All cineangiograms were taken during inspiration using a $23 \mathrm{~cm}$ Philips image intensifier tube and recorded on $35 \mathrm{~mm}$ film at 80 frames per second.

The vertical image-tube to table-top distance was carefully measured and recorded in each study. Ventricular volumes were determined from the single plane cineangiograms using the area-length method (Greene et al., 1967) and corrected for image magnification. In each state, a corresponding sinus conducted beat within the first four cycles after injection was analysed. All dimensional values were corrected for body surface area.

The total ejection fraction (EF) was calculated as

$$
\mathrm{EF}=\frac{\mathrm{EDV}-\mathrm{ESV}}{\mathrm{EDV}}
$$

where EDV is end-diastolic volume and ESV endsystolic volume determined angiographically. In cases with mitral regurgitation the forward stroke volume was determined independently by the Fick method before and after nitroglycerin.

The mean rate of circumferential fibre shortening was defined as the extent of shortening of the calculated minor internal circumference between end-diastole and end-systole divided by the period of systolic ejection. Since this period includes part of the isovolumic phase, $50 \mathrm{msec}$ was subtracted from the total systolic period in all cases without mitral regurgitation (Karliner et al., 1971).

All statistical comparisons were performed with Student's paired $t$ test.

\section{Results}

The Table summarizes the dimensional and haemodynamic effects of nitroglycerin in patients with and without mitral regurgitation.

\section{Effect on ventricular volume}

The most consistent feature associated with nitroglycerin was the reduction in left ventricular enddiastolic volume in all patients studied (Fig. I). This occurred in both groups despite the significant difference in average resting end-diastolic volumes; $82 \mathrm{ml} / \mathrm{m}^{2}$ for group I and $159 \mathrm{ml} / \mathrm{m}^{2}$ for group 2 . In patients without mitral regurgitation, there was a corresponding reduction in the average end-systolic

TABLE I Effect of nitroglycerin on left ventricular volumes and haemodynamics

\begin{tabular}{|c|c|c|c|c|c|c|c|c|c|c|}
\hline Case No. & Age & Sex & Diagnosis & \multicolumn{2}{|c|}{$\begin{array}{l}\text { Heart rate (beats/min) } \\
\text { Control Nitroglycerin }\end{array}$} & $\begin{array}{l}\text { Peak LV } \\
\text { (mmHg) } \\
\text { Control }\end{array}$ & $\begin{array}{l}\text { stolic pressure } \\
\text { Nitroglycerin }\end{array}$ & \multicolumn{3}{|c|}{$\begin{array}{l}\text { LV end-diastolic pressure } \\
(m n H g)\end{array}$} \\
\hline \multicolumn{11}{|c|}{ Group I: Without mitral regurgitation } \\
\hline I & 60 & $\mathrm{~F}$ & $\mathrm{CAD} \uparrow$ & 83 & 69 & 170 & 150 & 14 & 4 & \\
\hline 2 & 48 & $\mathrm{M}$ & CAD & $8 I$ & 69 & 122 & II 5 & 10 & $\begin{array}{l}4 \\
4\end{array}$ & \\
\hline 3 & 44 & $\mathbf{M}$ & CAD & 82 & 94 & 125 & II5 & 8 & $\begin{array}{l}4 \\
3\end{array}$ & \\
\hline 4 & 64 & $\mathrm{~F}$ & CAD & 62 & 66 & 112 & 89 & 8 & 8 & \\
\hline 5 & 48 & $\mathbf{M}$ & CAD & 80 & 95 & 188 & 180 & 16 & 10 & \\
\hline 6 & 48 & $\mathbf{M}$ & CAD & 71 & 79 & 124 & 129 & 18 & 16 & \\
\hline 7 & 58 & $\mathbf{M}$ & CAD & 65 & 65 & 105 & 110 & 24 & 20 & \\
\hline 8 & 60 & $\mathrm{~F}$ & CAD & 88 & 86 & 158 & 145 & 8 & 8 & 5 \\
\hline \multicolumn{4}{|l|}{ Mean } & 77 & 78 & 138 & 129 & 13 & 9 & \\
\hline \multirow{2}{*}{\multicolumn{6}{|c|}{ Group 2: With mitral regurgitation }} & \multicolumn{2}{|c|}{$P<0.05$} & \multicolumn{2}{|c|}{$\mathbf{P}<0.01$} & \\
\hline & & & & & & & & \\
\hline 9 & $6 I$ & $M$ & CAD & 65 & 71 & 90 & 90 & 20 & 25 & \\
\hline 10 & 46 & $\mathbf{M}$ & CAD & 88 & 79 & 142 & 128 & 4 & II & \\
\hline II & 59 & $M$ & CAD & 79 & 79 & 135 & 120 & 20 & 19 & \\
\hline 12 & 53 & $\mathbf{M}$ & CAD & 68 & 94 & 140 & 130 & 12 & 8 & \\
\hline 13 & 40 & $\mathbf{M}$ & CAD & 60 & 66 & 102 & IIO & 4 & 6 & \\
\hline 14 & 39 & $\mathrm{~F}$ & RHD $\ddagger$ & 79 & 71 & 105 & Iro & 21 & 16 & 1 \\
\hline 15 & 60 & $\mathbf{M}$ & RHD & 96 & 96 & 113 & 105 & 14 & I0 & \\
\hline 16 & 46 & $\mathbf{F}$ & RHD & 100 & 105 & 119 & 115 & 10 & I0 & \\
\hline 17 & 28 & F & RHD & 60 & 66 & 105 & 105 & 12 & 12 & \\
\hline \multirow[t]{2}{*}{ Mean } & & & & \multirow{2}{*}{\multicolumn{2}{|c|}{ NS }} & \multirow{2}{*}{\multicolumn{2}{|c|}{ NS }} & 13 & 13 & \\
\hline & & & & & & & & NS & & \\
\hline
\end{tabular}

Abbreviations: ${ }^{\star} \mathrm{Vcf}=$ circumferential fibre shortening rate. $+\mathrm{CAD}=$ coronary artery disease. $\ddagger \mathrm{RHD}=$ rheumatic heart disease $; \mathrm{NS}=8$ significance $(P>0.05)$. 
volume from 38 to $26 \mathrm{ml} / \mathrm{m}^{2}$, accounting for a significant increase in the mean ejection fraction from 0.53 to 0.64 . Conversely, in patients with mitral regurgitation, the average end-systolic volume did

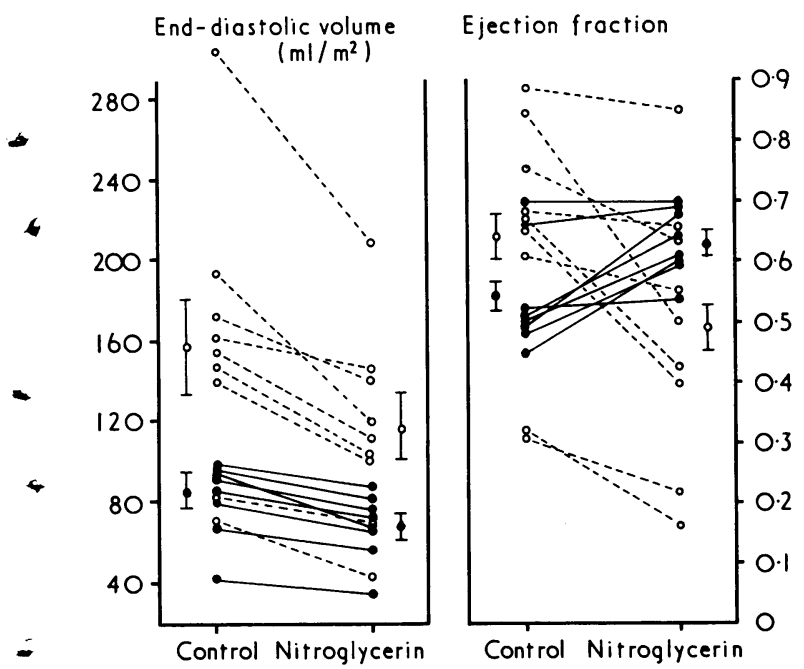

FIG I Effect of nitroglycerin on left ventricular enddiastolic volume and ejection fraction in patients without mitral regurgitation (solid circles) and patients with mitral regurgitation (open circles). Vertical bars represent standard error of the mean. not change appreciably with nitroglycerin (64 to $65 \mathrm{ml} / \mathrm{m}^{2}$ ), whereas the total mean ejection fraction fell significantly from 0.65 to 0.52 (Fig. I).

The initial size of the ventricular cavity did not appear to influence the results since the ejection fraction fell in those patients with mitral regurgitation in whom the end-diastolic volume was within normal limits.

\section{Effect on regurgitant flow}

The effect of nitroglycerin on the distribution of the total ejectate was determined in 4 patients with mitral regurgitation in whom Fick cardiac outputs were obtained in both states. Nitroglycerin produced only a slight and insignificant decrease in the effective cardiac index in patients without mitral regurgitation ( 3.2 to $\left.3.01 . / \mathrm{m}^{2}\right)$. Similarly, the measured effective cardiac index in 4 patients with mitral regurgitation was unchanged with nitroglycerin $(3.4$ to $\left.3.31 . / \mathrm{m}^{2}\right)$. However, since the ejection fraction in these cases fell with a concomitant decrease in enddiastolic volume (findings indicating a decreased stroke volume from the left ventricle) and since forward stroke volume through the aortic valve (as measured by the Fick method) was unchanged, the regurgitant volume must be considerably diminished after nitroglycerin. Indeed, in one patient after nitroglycerin, mitral regurgitation could not be de-

\begin{tabular}{|c|c|c|c|c|c|c|c|c|c|}
\hline \multicolumn{2}{|c|}{ kle/index $\left(\mathrm{ml} / \mathrm{bt} / \mathrm{m}^{2}\right)$} & \multicolumn{2}{|c|}{ Mean Vcf* $($ circ/sec $)$} & \multicolumn{2}{|c|}{ End-diastolic vol. } & \multicolumn{2}{|c|}{$\begin{array}{l}\text { End-systolic vol. } \\
\left(\mathrm{ml} / \mathrm{m}^{2}\right)\end{array}$} & \multicolumn{2}{|c|}{ Ejection fraction } \\
\hline rol & Nitroglycerin & Control & Nitroglycerin & $\begin{array}{l}\left(\mathrm{ml} / \mathrm{m}^{2}\right) \\
\text { Control }\end{array}$ & Nitroglycerin & $\begin{array}{l}\left(\mathrm{ml} / \mathrm{m}^{2}\right) \\
\text { Control }\end{array}$ & Nitroglycerin & Control & Nitroglycerin \\
\hline & 40 & $I \cdot 4 I$ & I.97 & 69 & 58 & 25 & 18 & 0.64 & 0.69 \\
\hline & 45 & $1 \cdot 52$ & $1 \cdot 08$ & 94 & 69 & 44 & 24 & 0.53 & 0.65 \\
\hline & 43 & $\mathrm{I} \cdot 38$ & $1 \cdot 38$ & 86 & 70 & 44 & 27 & 0.49 & 0.61 \\
\hline & 44 & 0.92 & $1 \cdot 18$ & 81 & 69 & 40 & 25 & 0.51 & 0.64 \\
\hline & 24 & $I \cdot 33$ & $1 \cdot 43$ & 42 & 35 & 24 & II & 0.43 & 0.69 \\
\hline 2 & 47 & 0.70 & $1 \cdot 35$ & 98 & 89 & 49 & 42 & 0.50 & 0.53 \\
\hline ' & 48 & 0.39 & 0.64 & 94 & 83 & 52 & 35 & 0.45 & 0.58 \\
\hline & 54 & $1 \cdot 62$ & 1.50 & 93 & 77 & 28 & 23 & 0.70 & 0.70 \\
\hline$\dot{-}$ & 43 & $\mathrm{I} \cdot \mathrm{I} 6$ & $I \cdot 32$ & 82 & 69 & 38 & 26 & 0.53 & 0.64 \\
\hline \multirow[t]{4}{*}{ NS } & & \multicolumn{2}{|l|}{ NS } & \multicolumn{2}{|c|}{$P<0.001$} & \multicolumn{2}{|c|}{$\mathbf{P}<0.001$} & \multicolumn{2}{|c|}{$P<0.01$} \\
\hline & 34 & 0.60 & 0.35 & 306 & 210 & $2 I I$ & I76 & 0.31 & 0.16 \\
\hline & 37 & 3.46 & $1 \cdot 90$ & 70 & 43 & 7 & 6 & 0.90 & 0.86 \\
\hline & 32 & 0.91 & 0.37 & 173 & I4I & IIO & 109 & 0.36 & 0.23 \\
\hline \multirow[t]{3}{*}{1} & 54 & $\mathrm{r} \cdot 95$ & 0.82 & 140 & 100 & 54 & 46 & 0.61 & 0.54 \\
\hline & 60 & 2.01 & $1 \cdot 68$ & 194 & 120 & 31 & 60 & 0.84 & 0.50 \\
\hline & 53 & 0.74 & 0.84 & 147 & 102 & 49 & 49 & 0.67 & 0.52 \\
\hline \multirow[t]{4}{*}{$>$} & 74 & 1.95 & $\mathbf{I} \cdot 88$ & 155 & 140 & 48 & 66 & 0.69 & 0.53 \\
\hline & 47 & 0.88 & $\mathbf{I} \cdot 30$ & 82 & 70 & 25 & 23 & 0.70 & 0.67 \\
\hline & 95 & $\mathrm{I} \cdot \mathrm{I} 4$ & $1 \cdot 16$ & 162 & I47 & 43 & 52 & 0.74 & 0.65 \\
\hline \multirow{2}{*}{\multicolumn{2}{|c|}{$<0.005^{34}$}} & $1 \cdot 52$ & $I \cdot 14$ & & II6 & \multirow{2}{*}{\multicolumn{2}{|c|}{ NS }} & & 0.52 \\
\hline & & \multicolumn{2}{|c|}{ NS } & \multicolumn{2}{|c|}{$P<0.005$} & & & \multicolumn{2}{|c|}{$\mathbf{P}<0.005$} \\
\hline
\end{tabular}


tected angiographically. While it is unfortunate that reduction of mitral regurgitation was not quantitated in all cas es, we note that the directional changes induced by nitroglycerin in the end-diastolic volume and ejection fraction were uniform in all patients studied.

\section{Effects on haemodynamics}

In patients without mitral regurgitation, there were no significant alterations in heart rate, mean rate of circumferential fibre shortening, or stroke index (Table) with nitroglycerin. The peak left ventricular systolic pressure was reduced significantly.

In patients with mitral regurgitation, no significant change in heart rate or peak systolic left ventricular pressure with nitroglycerin was present at the time the angiograms were performed. Though the mean circumferential fibre shortening rate was only reduced from $I \cdot I 8$ to $I \cdot I 4 \mathrm{circ} / \mathrm{sec}$ for the group, it was of interest that in all 5 patients with mitral regurgitation and coronary artery disease the mean circumferential fibre shortening rate decreased by 43 per cent from $1 \cdot 79$ to $1 \cdot 02 \mathrm{~cm} / \mathrm{sec}$ (Fig. 2) $(P<0.05)$.
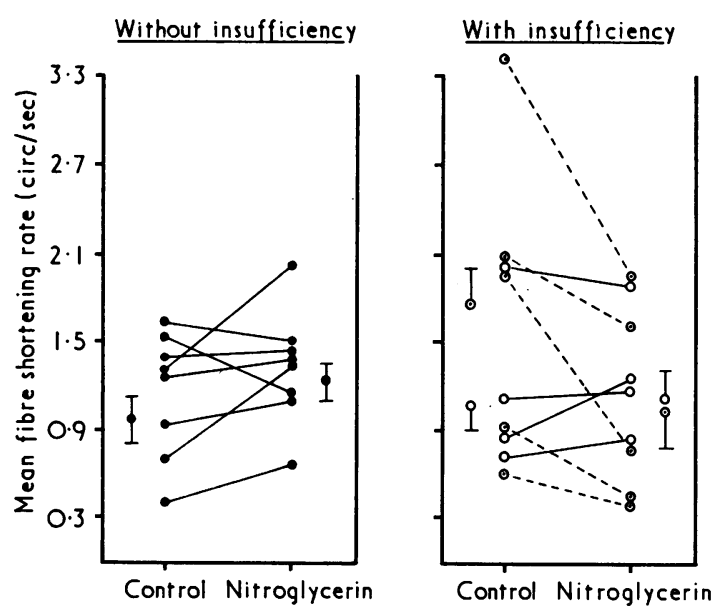

FIG 2 Effect of nitroglycerin on the mean fibre shortening rate in patients without mitral regurgitation (solid circles), patients with mitral regurgitation secondary to coronary artery disease (open circles with central dot), and patients with rheumatic mitral regurgitation (open circles). Vertical bars are the standard error of the mean.

\section{Discussion}

In this study, administration of nitroglycerin to patients without mitral regurgitation resulted in reduction of ventricular dimensions, both at endsystole and end-diastole. Earlier studies by Mason and Braunwald (1965) have shown that nitroglycerin causes venous vasodilatation, peripheral venous pooling, and reduction of external cardiac dimensions (Williams et al., 1965). Lee et al. (1970) measured this effect by indicator dilution studies, and noted that in 9 patients end-diastolic volume and stroke volume were reduced by 26 and 27 per cent, respectively.

The present study using angiocardiography differs in design from those previously in that the effect of nitroglycerin is studied after the subsidence of tachycardia. It is noteworthy that ventricular volume remains reduced and that stroke volume is maintained by an increased ejection fraction. While not establishing the mechanism of action of nitroglycerin, these results confirm the previous observations and indicate further that reduction of ventricular volume (and presumably of oxygen consumption) persists beyond the phase of tachycardia.

However, the patients with mitral regurgitation responded differently. Nitroglycerin in all these patients did decrease end-diastolic volume, but the ejection fraction was now reduced. In 4 patients, forward cardiac output measured directly was unchanged and thus the degree of mitral regurgitation was reduced. One possible explanation is the opportunity for better coaptation of the mitral leaflets in the less dilated ventricle. Alternatively, with the reduced volume, normal segmental wall kinetics may be restored in patients with papillary muscle dysfunction.

Finally, we are unable to explain fully the apparent deterioration in ventricular haemodynamics in patients with ischaemia and mitral regurgitation after nitroglycerin. If the mitral valve is incompetent, the volume of the left ventricle diminishes rapidly with the onset of systolic contraction. According to Eckberg et al. (1973) almost 50 per cent of the regurgitant volume is delivered to the left atrium before aortic valve opening. But the energy cost of ventricular function is in part dependent on peak developed stress which occurs at or coincident with aortic valve opening (Mirsky, 1969; Burns et al., 1971). Though end-diastolic volume was reduced after nitroglycerin, ventricular volume at aortic valve opening is not known and is perhaps unchanged or increased. Studies are in progress to test this hypothesis, since it may in part explain an unfavourable response to mitral valve replacement seen in some patients with ischaemic heart disease and mitral regurgitation.

\section{References}

Braunwald, E. (1969). Thirteenth Bowditch lecture: the determinants of myocardial oxygen consumption. Physiologist, 12, 65 . 
Burns, J. W., Covell, J. W., Myers, R., and Ross, J., Jr. (I97I). Comparison of directly measured left ventricular wall stress and stress calculated from geometric reference figures. Circulation Research, 28, 6II.

Eckberg, D. L., Gault, J. H., Bouchard, R. L., Karliner, J. S., and Ross, J., Jr. (1973). Mechanics of left ventricular contraction in severe mitral regurgitation. Circulation, 47, 1252.

Fam, W. M., and McGregor, M. (1964). Effect of coronary vasodilator drugs on retrograde flow in areas of chronic myocardial ischemia. Circulation Research, 15, 355.

Gorlin, R., Brachfeld, N., MacLeod, C., and Bopp, P. (1959). Effect of nitroglycerin on the coronary circulation in patients with coronary artery disease or increased left ventricular work. Circulation, 19, 705.

Greene, D. G., Carlisle, R., Grant, C., and Bunnell, I. L. (1967). Estimation of left ventricular volume by one-plane cineangiography. Circulation, 35, 61.

Karliner, J. S., Gault, J. H., Eckberg, D., Mullins, C. B., and Ross, J., Jr. (197I). Mean velocity of fiber shortening. A simplified measure of left ventricular myocardial contractility. Circulation, 44, 323.
Lee, S. J. K., Sung, Y. K., and Zaragoza, A. J. (1970). Effects of nitroglycerin on left ventricular volumes and wall tension in patients with ischaemic heart disease. British Heart Fournal, 32, 790.

Marchetti, G. V., Merlo, L., and Antognetti, R. M. (1964). The effects of nitroglycerin on the coronary blood flow and oxygen consumption of the myocardium in anesthetized dogs. American fournal of Cardiology, 13, 51.

Mason, D. T., and Braunwald, E. (1965). The effects of nitroglycerin and amyl nitrite on arteriolar and venous tone in the human forearm. Circulation, 32, 755.

Mirsky, I. (1969). Left ventricular stresses in the intact human heart. Biophysical fournal, 9, 189.

Perloff, J. G., Ronan, J. A., Jr., and de Leon, A. C., Jr. (1965). The effect of nitroglycerin on left ventricular wall tension in fixed orifice aortic stenosis. Circulation, 32, 204.

Williams, J. F., Jr., Glick, G., and Braunwald, E. (1965) Studies on cardiac dimensions in intact unanesthetized man. V. Effects of nitroglycerin. Circulation, 32, 767.

Requests for reprints to Dr. Allan D. Sniderman, Cardiology Division, Royal Victoria Hospital, Montreal I 12, P.Q., Canada H3A rAr. 